Western Washington University Western CEDAR

\title{
Artists as catalysts: the ethical and political possibilities of teaching artists in literacy classrooms
}

Anne Crampton

Western Washington University, anne.crampton@wwu.edu

Cynthia Lewis

Follow this and additional works at: https://cedar.wwu.edu/woodring_dei

Part of the Education Commons

\section{Recommended Citation}

Crampton, A. and Lewis, C. (2020), "Artists as catalysts: the ethical and political possibilities of teaching artists in literacy classrooms", English Teaching: Practice \& Critique, Vol. 19 No. 4, pp. 447-462. https://doi.org/10.1108/ETPC-11-2019-0154

This Article is brought to you for free and open access by the Woodring College of Education at Western CEDAR. It has been accepted for inclusion in Woodring Scholarship on Diversity, Equity, Inclusion by an authorized administrator of Western CEDAR. For more information, please contact westerncedar@wwu.edu. 


\title{
Artists as catalysts: the ethical and political possibilities of teaching artists in literacy classrooms
}

\author{
Anne Crampton \\ Department of Special Education, Woodring College of Education, \\ Western Washington University, Bellingham, Washington, USA, and \\ Cynthia Lewis \\ Department of Education, University of California Santa Cruz, Santa Cruz, \\ California, USA
}

\begin{abstract}
Purpose - This study aims to discuss the ethical and political possibilities offered by the presence of teaching artists (TAs) and visual artwork in racially and culturally diverse high school literacy (English Language Arts) classrooms.

Design/methodology/approach - This study explores episodes from two separate ethnographic studies that were conducted in one teacher's critical literacy classroom across a span of several years. This study uses a transliteracies approach (Stornaiulo et al., 2017) to think about "meaning-making at the intersection of human subjects and materials" (Kontovourki et al., 2019); the study also draws on critical scholarship on art and making (Ngo et al., 2017; Vossoughi et al., 2016). The TA, along with the materials and processes of artmaking, decentered the teacher and literacy itself, inviting in new social realities.

Findings - TAs' collective interpretation of existing artwork and construction of new works made visible how both human and nonhuman bodies co-produced "new ways of feeling and being with others" (Zembylas, 2017, p. 402). This study views these artists as catalysts capable of provoking, or productively disrupting, the everyday practices of classrooms.

Social implications - Both studies demonstrated new ways of feeling, being and thinking about difference, bringing to the forefront momentary possibilities and impossibilities of complex human and nonhuman intra-actions. The provocations flowing from the visual artwork and the dialogue swirling around the work presented opportunities for emergent and unexpected experiences of literacy learning.

Originality/value - This work is valuable in exploring the boundaries of literacy learning with the serious inclusion of visual art in an English classroom. When the TAs guided both interpretation and production of artwork, they affected and were affected by the becoming happening in the classroom. This study suggests how teaching bodies, students and artwork pushed the transformative potential of everyday school settings.
\end{abstract}

Keywords Critical literacy, New literacies, Literacy and identity, Arts and literacy, Embodiment and literacy

Paper type Research paper

This study discusses the ethical and political possibilities offered by the presence of visiting teaching artists (TAs) in high school classrooms. TAs and their work make visible how both human and nonhuman bodies co-produce "new ways of feeling and being with others" (Zembylas, 2017, p. 402), such as new ways of thinking about difference. For this reason, we view them as catalysts capable of provoking or productively disrupting and decentering the 
everyday practices of classrooms. The processes of both creating and responding to visual artwork presented opportunities for emergent and unexpected experiences of literacy learning.

As the call for this special issue on teaching, learning and becoming in a "post-world" suggests, we understand literacy to be made up of bodies, human and nonhuman. We see it as run through with feelings that change over time, always infused with identities that change, as well. We view literacy as change, too, an experience of creating something new: transforming signs, yes, but also finding change in an un-making or deferral of meaning that falls or scrambles outside of signs, always becoming. Literacy viewed this way is certainly an entanglement, and in our exploration of TAs in English Language Arts (ELA) classrooms, it existed in intra-actions between the artists, students, and the visual art being discussed and produced, all of which provoked complex ways of exploring and asserting subjectivities for the students in the two studies.

TAs have been part of mainstream education offerings in the USA since the 1920s, when they were included in the programming at settlement houses and schools as a means to share the arts with (especially urban) students who were not thought to have access to artistic instruction in the course of their schooling (Rabkin, 2013). Today this work carries similar goals: artists are enlisted to guide students in learning how to create art and/or to provoke learning through discussions about art. In the USA and globally, the arts are not consistently supported in programing budgets, and arts integration across different disciplines is even more precarious. In both of our studies, as is often the case, the presence of TAs in a literacy classroom was a luxury, the result of an application for funding through a grant.

Here, we feature two vignettes from two classroom ethnographies conducted in a US school district in one teacher's classroom about five years apart. In each ethnography, visiting artists served as unplanned participants and catalysts for participatory politics among youth and adults in the settings. We ask: How does a new teaching body in the classroom shift the socio-material landscape and with what consequences for structures, relationships and meaning-making? The already-established class and the familiar school became different when a TA entered the scene. In particular, racial and cultural identities appeared to be newly visible, racial injustices were articulated freshly in artistic interpretation and creative productions, forcing tensions to the surface in ways that were disruptive and difficult, but also generative for learning.

Our two studies are linked by a single teacher in a large, diverse urban district in the upper Midwest who opened her classroom to us for extended ethnographic stays. She valued the addition of TAs in her high school ELA courses, applying for and receiving funding to support their work with her students in the literary arts (e.g. theater and spoken word) as well as visual arts (e.g. photography, film and murals), finding both to be an integral part of a multimodal literacy educational experience. Far from riding the "maker" movement wave that disregards the histories of making in nondominant cultural groups, the teacher's goals included artistic production and critique as well as opportunities for her students to engage in critical dialogic interactions and intra-actions with each other, the artwork, materials to create art, the artists and their relationships with justice and injustices both in and outside the classroom. We point this out as this teacher would be the first to hope for the emergence of new social realities occurring with the addition of an effective TA in her classroom. It is also noteworthy that the racial and ethnic identities of the TAs differed from that of the classroom teacher, a White woman. Thus, they brought not only their artistic expertise and critical approaches to pedagogy into the classroom, they also brought their physical bodies as artists of color with immigrant perspectives, and a willingness to make their identities, histories and activism part of their talk and work with students. 
The separate ethnographic studies are linked together through several common features. As mentioned, the teacher was the same for both studies: a veteran teacher with longstanding commitments to critical literacy and dialogic instruction in racially and culturally diverse urban schools. Thus, the critical quality of these ethnographic studies was not a critique of the teacher-participant in the study or of her classrooms or schools. Rather, our critical ethnographic research aligns with the critical activism of the teacher's work with her students. In both cases, we were not detached observers but participants over long stretches of time, working with students in ways that -much like the other adults in the rooms revealed our social and political commitments. In addition, links between these studies included the fact that the visiting artists - photographer and muralist - were known in the community as activist artists who were politically engaged; they were particularly interested in talking and thinking about nondominant experiences of being raced or being from immigrant families. Both artists sought to hear from all of the voices in these racially, ethnically, linguistically, spiritually and economically diverse classrooms.

\section{Theoretical perspectives and methodological approaches}

We drew from two areas of inquiry that are at once theoretical and methodological: transculturalism and transliteracies. As we explain in this section, both depend on embodied and metaphorical mobilities, and both help us to understand how artistic intervention in ordinary classroom life can affect relationships as they spark and shift across difference. As we discuss each, we move fluidly between theory and method because separating the theory from analytic methods would detract from the recursive and reflexive nature of the inquiry. As Volosinov (1987, p. 79) stated: "In order to understand this 'scenario', it is essential to reconstruct all those complex social interrelations of which the given utterance is the ideological refraction".

Translocalism is an iteration of cosmopolitanism that takes into account the mobility of students in their everyday border crossings as well as their more dramatic migrations, arriving at the classroom - a particular time and place - with all of their diverse and fluid linguistic, cultural, racial, ethnic, economic and gender identities, different knowledge and histories. Rather than imagining an idealized "global citizen," translocalism points to the gut-wrenching complexity of feeling loyalties to both local and global contexts (Brickell and Datta, 2011). We use the concept of "proper distance" (Chouliaraki, 2011; Silverstone, 2003) as an orientation toward the other which refers to being close enough for care and compassion, but not so close that we cannot see or accept difference. Admitting that we cannot know the other becomes an ethical, "proper" correction to this improper closeness, and, yet, in a difficult balance, we must draw close enough to continue to feel something for/ with our others. Thus, emotional engagement (proximity) combined with criticality (distance) makes responsible action possible. Building from proper distance, our analytic process involved noting and unpacking moment-to-moment interactions/intra-actions that create shifting distances between people, bodies, objects and signs, while always remaining situated within social/societal power structures.

A transliteracies framework goes beyond multimodality to include not only digital and networked literacies to look at "what moves" across bodies and texts of all kinds, including human and non-human objects, feelings, all as resources both indescribable and remarkedupon (Stornaiuolo et al., 2017, p. 70). The framework considers how meaning emerges, travels, evolves and dissolves over time. Key to this framework is the understanding that overlapping literacies contain within them inequities of power, "open[ing] some opportunities and foreclose[ing] others" (p. 70). In thinking about the literacies that emerged with the presence and activities introduced by the TAs, we were interested in what was 
made possible, what was amplified and what was "muffled" by this mobility (p. 81). The concepts of uptake and resonance from this framework were also used as tools of inquiry that guided our analytic process. Uptake refers to the process of tracing how meaning shifts - related to time, scale, roles and relationships - and how meaning is attended to, by whom, and with what authorization (e.g. experience, text, teacher and institution). As Stornaiuolo et al. (2017, p. 79) state, "entitlement rights" (Bloome and Egan-Robertson, 1993) can illuminate the micro-dimensions of power and ideology, especially as these rights have been shaped historically in relation to race and gender and have played out through people's everyday literacy practices. Uptake, in our studies, was made differently visible depending on whether visual art was a co-constructed text (mural) or a pre-existing object of inquiry (photo). Resonance notes how phenomena may "vibrate" (p. 82) when encountering other phenomena across time and space, a notion that was applicable in our collaborative work across two studies, which had some connection and disconnection in containing the same teacher and school district, but two researchers, two different groups of students, two different artforms and TAs and a distance of five years which presented different awareness and urgencies about racial, cultural and social injustices. Within each study, we noted what took hold in interaction as well as what kept moving and shifting.

The TAs, one a documentary photographer and the other a muralist, both embodied a lifelong commitment to social justice and public and political artmaking, a reminder that the long history of critically conscious community art is often overlooked amid the current trendiness and somewhat as cultural maker-spaces and do-it-yourselfers (Vossoughi et al., 2016). We draw on the tradition of artists as change agents, noting that the arts themselves are thought to open spaces for divergent thinking (Anderson et al., 2013; Kenny and Morrisey, 2020; Mardirosian and Lewis, 2016; Rasmussen, 2009). Indeed, John Latham and Barbara Steveni's Artist Placement Group (UK) sought to position the body of the artist as a professional outsider in a setting that was not typically associated with art (such as industry or politics), to disrupt and critique institutions and social conditions. While the artist's body is not necessarily out of place in a school setting, we explored the role of the TA as a contributing presence that allowed students and teacher to "create a time and space different from the end-oriented movement of schooling [...]" (Pindyck, 2016, p. 88) in a pedagogy of emergence. While it is often hoped that the TA will transform learning in some way, it is also important to note that the presence of these TAs was not marked as atypical for schools that employ artists. That is, from the perspective of anyone besides, perhaps, the host teacher, their role was not envisioned as a radical departure from typical school practices. They were meant to enhance the curriculum, in line with an already existing critical pedagogy, albeit one focused on critical text analysis and production rather than art creation and activism. Beyond the artists, we were struck by the physical presence of the visual art acting as a decentering force outside of individuals' processes of creating and responding to it in these literacy classrooms. This led us to consider post-human theories that emphasized intra-actions across the human and nonhuman bodies as entangled and shifting (Kuby and Crawford, 2018). No one entity held the center; the visual and spoken texts were messy, and were constantly changed by hands, words and gestures. As researchers, we individually and together made note of the infusion of "vitality" that seemed to enter with TAs and bring with it not only "novelty," but something that shifted power, creating ways of "being otherwise with others" (Zembylas, 2017, pp. 397-398). At the same time and amid this fluidity, the work in both classrooms pointed to the political and ethical potential of collectively responding to and creating art, especially when art is viewed as a means of critical resistance in educational settings (Kahne et al., 2014; Soep, 2014). Finally, we noted the precarity for some students to show up in resistance - undocumented immigrants, for 
instance - despite the optimistic theories of art and civic engagement/participatory politics, paradigms that too readily assume that youth inherently have citizenship and are welcomed to engage in democracy (Ngo et al., 2017).

The data collection and ethnographic research methods were similar across the two studies. Both studies occurred for a full academic year, with hundreds of hours spent in the settings. Our time with these students, the teacher and the TAs was documented in field notes and photos, as well as audio and video recordings that were subsequently transcribed. Data for the recordings included semi-structured interviews with students and teachers, informal and formal class discussions and countless everyday interactions. Data directly related to the TAs included the artwork being created and responses to visual art through classroom dialogue. Thanks to the length of time in these settings, our understanding of the experiences explored here was informed by what the students had previously read, seen and created, as well as what transpired after the artists left them.

\section{Settings: two studies}

The setting for Study One (“The Photograph”) was East High School (1,250 students), a diverse high school in a fairly large upper Midwest city school district. Enrollments had been steadily declining for five years during which the school had shifted from a neighborhood school for primarily White working-and-middle class families to a commuter school attended by 39\% English language learners, and $90 \%$ students of color (46\% African or African American, 33\% Latino/a, 8\% Asian American, 3\% American Indian and 10\% White). A total of $83 \%$ of students qualified for free and reduced lunch. The class was representative of this demographic distribution. As a White Jewish woman who was a young child in 1950s Chicago, with my Russian immigrant grandparents living downstairs, I (Cynthia) learned from the adults around me to be skeptical of the dominant institutions from which they were excluded at the time. Eventually, we made the upwardly mobile move to a primarily Jewish suburb famous for a 1,977 Illinois Supreme Court decision to allow a Neo-Nazi group to march, although local attorneys argued that the group's swastikas would be felt as a physical attack among the many holocaust survivors who lived there. These experiences shaped my teaching and research interests in the complex social politics of literacy and learning in racially and ethnically diverse classrooms. None of these experiences changes the fact that I am also a cis-female White teacher with institutionalized and personal privileges. Beyond the year of this study, I was fortunate to collaborate with the teacher on several projects and one school-wide program, and have always been inspired by her work in forging meaningful connections between youth and community partners.

The setting for Study Two (The Mural) was Midtown High School, a large (1,778 students), diverse high school in the same Midwest city school district. While the other schools in the district were more segregated, either with mostly White students, or with mostly students of color, Midtown and the students in this classroom straddled the racial divides in the district. It was racially and culturally mixed, with roughly $40 \%$ African (Somali) and African American students, 40\% White students, 18\% Latinx students and $2 \%$ Indigenous students. This school, diverse as it is, affirms White identities as all or almost all schools in the USA do, and this had an impact on researcher position and identity. Along with many who labor in US education, I (Anne) identify as White and female, a product of public schools, the daughter of a teacher and long-time teacher in urban schools. Thus, the setting was familiar, and even more so because I shared many demographic features (whiteness, age, gender and teaching background) and ideological commitments (critical and striving to do anti-racist literacy education) with the teacher. Beyond this, after spending a year with this group of students, I felt that my presence was mostly 
unremarkable; I was a researcher, yes, but I was another body in the room who would talk to anyone, offer ideas and small-group or individual support, and serve as audience; unlike the TA and teacher, I was not responsible for making and enacting daily plans.

\section{Study one: the photograph}

In this study, a TA visited a junior/senior English class to discuss his photographs with the students. His photography was grounded in the surrounding community, with names for his collected work drawn from local areas and landmarks that were part of these students' lives, including the neighborhood surrounding the school. For example, he staged a gallery walk of very large versions of his photographs that were focused on a city street that spans 15 neighborhoods and, as he put it, "connects the trendiest and poorest communities in the [city]," thus increasing community-based art and access to art. In addition to its focus on community settings, the TA's work focused on the complexity of race and racial identity, and as such, it aligned with the kinds of conversations students had already been having in the course, conversations that often centered on students' interests and concerns about racial representations and lived identities. Despite the local subjects of his photos, a stated goal the artist had for sharing his photography was to get viewers to think of themselves as removed from themselves, thus making the familiar strange.

The English class focused on media analysis and documentary film production in an English/History block that met state and district standards for both subjects. With a commitment to providing students with opportunities for complex intellectual engagement, the course involved reading and writing in the process of analyzing and producing media texts, including collage, digital stories, podcast memoirs and, ultimately, a documentary film. The class discussion we analyze took place in February, just one month before students were to pitch topics for their final film projects. The teacher's expressed goal for the TA's visit was for the students to "pick his brain" and get advice from a "real artist" about how he narrows a topic and gets across a central message. She did not make many comments throughout the 2-hour class, but when she did, it was typically about photography or filmmaking techniques. The TA asked students for the talk to be informal "to have dialogue while I'm showing my work." In the time he had with the students, the TA met this goal, discussing, for example, the way that photographs are organic and they reflect who you are at the time. Years later, he suggested, you might interpret them differently.

Mostly, however, the TA and the students were driven to examine the complexities of racial identity. When the topic turned to technique or craft, a provocative question or wondering would bring the conversation back to racial identity. I had seen this TA speak with students before, and although his photographs were always related to racial identity, this time something different was happening: these photos, this class and the TA's exploration into his own Asian identity through the photographs he shared - all of this catalyzed a particular kind of learning that looped through and around and back again from photo to deep examinations of racial identity, each time engaging students in increasingly complex questions and thoughts about image, self and world. After a long conversation about a Korean adoptee's racialized identity that will be discussed in this section, the TA revealed a tension in his artistic process which he said was at the heart of the photography book focused on Asian diasporic identities that he shared that day:

I think the larger question is whoever I photograph, I find some kind of commonality; there's something that is - seems familiar to me, but at the same time, it feels exotic. It's like, "Wow, I can understand that, but, boy, I don't know what it's like to be you." And it's that tension between those two, I think, is what I'm interested in. 
Later, the TA referred to his book as an "ethnocentric tour," a concept that was woven throughout the conversation to refer to the way viewers interpret the identities of others through their own ethnocentric filters. From the start, he foregrounded this concept through his own struggle with his Asian identity and adolescent desire to belong rather than feel exotic. He explained to students that he was the first in his family to be born in the USA and that he is a native to the state in which they live. Everyone else in his family, however, was from a small village in China and immigrated illegally. In fact, his father, he told the students, "purchased an identity." He explained that as an only Asian boy in school, he perceived himself as white, so that when another Asian boy came to the school, he avoided him. "Why would you think I would avoid someone who looked like me?" he asked the students. He further explained:

See, it's not like you grow up with a mirror in front of you; I thought I was like everyone else. I thought I was like what I saw. And when I saw this Asian kid, I thought, "Geez, he stands out." Made me feel uncomfortable.

If the new boy was distant from other White children in being Asian, then he must also see himself as different and distant from other children. The boy became a kind of mirror for him to view - from a distance - the self he thought he knew, the self who fit into whitestream spaces. In beginning his conversation with the students in this manner, he created a space for students to interpret the multiple locations they, too, traversed as they struggled to understand the photographs and the subjectivities represented therein.

After this introduction, he asked the students, "What am I?" Several students responded that he was "Asian" while others wondered how he might be Asian and a native of their state at the same time. Throughout this opening conversation, the photographer was willing to be questioned about his identity and never offered a definitive answer to the question of "What am I?" In this way, he amplified a subject of great interest and resonance to students. In fact, the question that recurred throughout the 2-h block was a question about the nature of identity: must one view racial identity as given and embodied, or is it more mobile, depending on translocal movements and locations? These positions get played out in the views of two engaged African American students: Vanessa and Shannon.

Vanessa lived in a first-ring suburb with her mother who identified primarily as White. She went to a nearby suburban school in 8th grade for a year but experienced intense racism that made her feel that she could not "survive" there. She told her mother "This is not me!" and began commuting to this city high school in 9th grade. Vanessa often talked about her experiences with racism and placed great value on the rootedness of a strong affiliation with African American identity. This sense of rootedness and the relationship between culture and race is at the heart of much of Vanessa's interpretations of texts and media as well as her contributions to dialogues. My (Lewis) field notes from the year of this classroom ethnography are rife with Vanessa's contributions, which often emerged as arguments that served as a catalyst for complex and sometimes difficult discussions. Shannon, also African American, had experienced gang violence up close, and as a mother to a young child, was somber and mature about the legacy of racism and its toll on Black communities. At the same time, she was a lighthearted high schooler who refused to be thwarted by this legacy. Despite her close friendship with Vanessa, her position in any discussion was to view identities as somewhat fluid, depending on individual desire. Black women, in particular, she argued, could choose how they want to look and be. Her analyses of texts and media contested limiting depictions of what it could mean to be Black, which she applied more generally to topics related to the lives of women of color. Intersection and shifting identities were in Shannon's comfort zone. The few White girls in the class generally found this 
position appealing, probably because it allowed them to avoid confronting power and race as directly as Vanessa's positions.

Within the first half hour of the discussion, the TA showed a section of a video he created to accompany his book. The section featured a young Korean American woman who talked at length about her racial identity as someone who was adopted by White parents. She felt fetishized in White communities, wanting, instead, to feel a part of the melting pot and not needing to think about race. This was disturbing to Vanessa, thus launching an extended conversation about the meaning of cultural identity and its relationship to race.

Vanessa: I feel bad for that girl:

TA: Why?

Vanessa: Because she can't be who she is because she grew up in America around white people, and now she wants to be what she sees; she can't be her.

TA: All right. So, I think that what you see, does it have more to do with what you're looking at or does it have more to do with you?"

After subsequent turns, the artist returned to this idea:

$T A$ : So I wanna get back to something. You felt sorry for this girl, the Korean adoptee [... ] but why do you feel sorry for her? Or does anyone else feel differently - this Korean adoptee who doesn't want anything to do with Korean culture, and [. . . ] andher Asian friends call her "white girl," to insult her.

Vanessa: That's sad.

TA: But she takes that as a compliment. Is it sad?

For the next $25 \mathrm{~min}$, the students and the artist discussed the meaning and dilemmas of racial identity. They inquired, pushed, challenged, recanted and reconsidered, with the TA discussing his own identity as enmeshed in popular culture ("Mary Tyler Moore" and "Jesus Christ Superstar" when his mom wanted him to pray to Buddha) and Midwestern whiteness while being recognized by others as Asian imbued with the meanings that others place on Asian identity:

Vanessa: I think, because she wasn't raised around Asian people, she didn't get to experience that culture of Asian - that's why - because I was kind of - I've been in a situation like that; I never hated being black or nothing like that, but when me and my sister went to a basically, all-white school in the suburbs, it was like we were the only black people in class [... ] so I see how she feels, and I feel bad for the girl; I just wanna ask you how do you feel about how - what she was saying about that stuff?

Two African American students, Shannon and Dasia, followed with a conversation about what happens when Black girls are said to be acting White. The TA asked if there is a right way to be Black and if that is the same thing this girl is experiencing:

TA: [...] But my point is if you look Asian, why do you feel sorry for the person 'cause they're not connected to what you think their country should be? 
Shannon agreed and asked why we should feel sorry for someone who wants to identify as White and is able to arrange her life to do so. She discussed a Black friend raised in a White family who "talked and acted and dressed" like all of their Black friends. Others draw on additional examples of people who act like those with whom they affiliate rather than the race they are perceived to be. Vanessa, returning to the photograph, quietly states that "that's not her" and "she's probably hurting on the inside".

Others are included in the discussion, of course. I feature Vanessa and Shannon because they represent the more extreme ends of the argument. Others are less certain and experiment with ideas. Perhaps culture is about where you grow up, some suggest, and who you hang out with. They all press each other to think deeply, question their assumptions and provide examples. The TA asks one of the speakers to clarify his position and then revoices the young man's answer. At one point, Vanessa's answer to why she feels sorry for the Korean adoptee is "Because I do" and Shannon replies "But you gotta tell him [TA] why".

Two things are particularly notable in this discussion. First is the TA's pedagogical skill, his way of treating students as intellectuals. He never talked down to them, instead asking provocative questions that are not asked for any larger purpose than to think about what art - in this case a series of photographs - does. What do these photos do to us? How do we interact with art? What can art teach us about ourselves, our cultures and our histories? There were no single stories in the classroom that day. There were provocations ("What do you think my ethnocentric filter is?") and there were probes:

(Well, this is a complicated subject, and I don't - you don't really know if she's conflicted or not - I think she probably is - but let's carry this on a little further [...]).

The second notable feature is perhaps specific to this conversation. As mentioned earlier, the intense and recursive focus on racial and cultural identity that was taken up by students and TA throughout the discussion was remarkable. Although the students were accustomed to talking about racial identity in class, even without the TA present, the focus on racial identity in this conversation was both multidimensional and laser-focused, we believe, because the art being shared by the TA was an extension of his lifelong struggle. He presented photographs from his book about the diasporic identities of Asian Americans, and the depth of his emotional experience - both the intensity and the ambivalence of that experience (How Asian am I? What does it mean for me to be Asian?) - resonated throughout the discussion. By way of the art and artist, the students' felt ideas about the nature of ethnic identity took hold. Was ethnic identity governed by the racialized body? Embraced or resisted at will? Treated with indifference? These questions took hold in the discussion. In other work (Crampton et al., 2017; Lewis and Tierney, 2013; Lewis, 2020), we argue that emotion is "mediated action" in that it is mediated by language, gesture, tone, etc. but it does something; it acts, it circulates and it mobilizes. (E)motion - as the word itself suggests - is in motion. Ahmed (2004, p. 120) refers to the "rippling effect of emotions" that "move sideways (through 'sticky' associations between signs, figures, and objects) as well as backward" with traces of history in the present. In this conversation, the TA shares his story and demands, gently, that students enter the abyss of identity exploration, expression and representation with him - through his history and his future as well as theirs. This is the meaning of uptake in the transliteracies approach (Stornaiuolo et al., 2017). Uptake "focuses on how researchers can trace ways people's bodies and material/semiotic objects respond to one another and otherwise make visible collaborative sense-making processes" that, drawing on Bakhtin (1986, p. 79), are both "historic and proleptic".

The material/semiotic objects in this vignette were the photographs themselves. While increasing immediacy, the photos also decentered their experiences with racial injustice or 
feelings of difference and placed them within the imagined experiences of the subjects in the photo ("That's not her" and "She's probably hurting on the inside"). Layering the power of visual/media texts atop the already-existing unease between different cultures and racialized identities, creates openings for productive tension, but also spikes the emotional intensity of classroom talk. Racism experienced in suburbs, the salve of popular culture, the resistance or embrace of identity and the seduction of fluid performativity that Shannon desired - sorting through all of it was their important work. Most likely, students did not learn to narrow their topics on that day, but from what I (Lewis) could see, they learned how to develop complex readings of photographs, and they learned something about the power of art to move them to feel and think together.

\section{Study two: the mural}

In this study, the same teacher invited a local muralist to work with seniors for a three-week block during their final semester to collectively design and paint a mural that depicted what was important and pressing to the group, both personally and at the societal level. The TA, originally from Mexico, had experience bringing together diverse cultural and political perspectives to make collective art. In his words:

The students I'm working with are Black, Somali, Latino, and Caucasian. I want to make sure everyone's voice is included, to know what they feel, and what they want to see different in the world.

The mural project that he facilitated was notable for the vigorous and often contentious discussions that raised serious questions about the role of art in civic dialogue and social change.

The students wanted to leave behind an enduring statement of truth about this moment in their lives and an imagination about what they wanted to see in the future. The mural was to cover a large wall near the English and Social Studies classrooms, a busy route on the way to the media center. In the planning stages, the group proposed ideas, going back and forth in dialogue until they agreed upon certain features of their design. These agreed-upon components were drawn and then projected onto the wall, where they were drawn again and finally spray and hand painted, using both graffiti and brush techniques. They agreed on a bright blue map of the USA in the center of the mural. They agreed on stately pine trees in the northwest corner of the map. Against this background, two hands reach out to touch each other from northeast to southwest, sort of like Adam and God on the Sistine Ceiling, with hands opening as though they might clasp, perhaps in a gesture of help. Outside of the map's borders, images depicted the degradation of the land, linking capitalism, colonialism and racial injustice in multiple ways. For instance, the graffiti-style words "can't breathe" appear next to a gas mask over polluting smokestacks and dollar signs while invoking Eric Garner's last words to the Staten Island police (Figure 1).

While the group agreed on many of the images and topics they wanted to show, there were some major conflicts that emerged because of divergent ways students wanted to show the problem of violence against Black lives. The heated discussions included all of the students in the class, the TA, teacher, adjacent teachers and administrators. The argument concerned how explicitly police violence might be linked to the contiguous history of racism in the USA, from slavery to Jim Crow to the Civil Rights era and up until today. Quite a few members of the class were active in protest movements like Black Lives Matter (BLM) and well-versed in prominent national stories like the deaths of Eric Garner and Michael Brown, and within the past year there had been two local cases of police violence against African American men that resulted in death, one of them a young man about the same age Travyon 


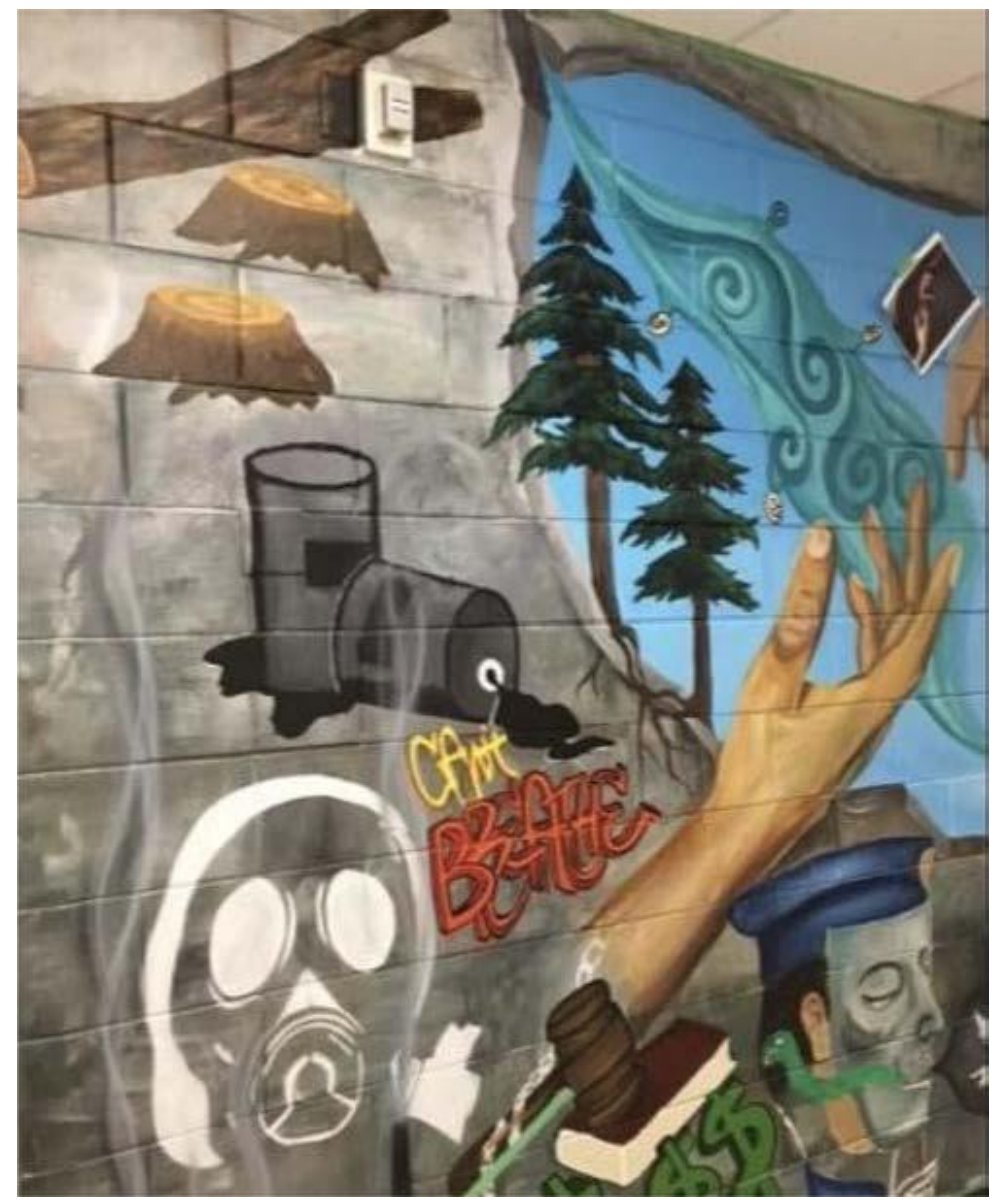

Figure 1.

Mural showing masked police with snake (lower right)

Martin had been at the time of his death. The topic was more than a topic: it was alive in the students, teachers, researchers and artists. However, when it came expressing BLM activism on the mural, the students - who were the designers - had mixed desires. The group agreed about the inclusion of an iconic Trayvon Martin-like figure, depicted in the lower right quadrant of the mural, in handcuffs and wearing a hoody. They disagreed about the depiction of the police officer. Below the map, there were two figures facing each other: an African or African American figure was positioned across from a White uniformed individual, a police officer, whose face was obscured behind an expressionless gray mask. A number of students wanted to show this officer wearing a Ku Klux Klan (KKK) hood or mask instead of the mask they eventually settled on. This was when things got contentious, because including an image of the Klan presented a problem to members of the class and the administration.

There were many reasons for the dispute, and notably, there were African American students on both sides of the argument: some students did not want to be confronted with images of the Klan on the wall every day, and, closer to home, one student's mother was an African American police officer, and the student objected to connecting the anonymous police officer with the KKK. Conversely, several African American students accused the administration and the teacher of trying to "whitewash" history by not allowing the KKK reference. In the end, the teacher felt she had to support the decision of the administration to block the KKK imagery. An activist African American girl railed against the silencing. 
Crying, voice shaking, she said that Midtown High was "a crock of shit. It acts like it's social justice, but it's all BS because you all are willing to shut down the real voice of students". One male student, also self-identified as both an activist and as African American and White, was so incensed by the silencing that he opted out of the production for a period of time, during which he stood to the side as constant witness, documenting but not participating in the creation of the artwork. His presence as a documentary photographer of the mural-making served to remind everyone that he did not approve of the censorship, and that he was watching, seeming to take grim pleasure in this observer-dissenter role (Crampton, 2019). His documentary allowed him to put proper distance between himself and the project, without necessarily putting this same distance between himself and the bodies in the room.

The muralist took up a quiet position amid the controversy. While he navigated and helped enact the artistic compromises the group made, he appeared to step back, which resulted in more weight on the shoulders of the students, as well as the classroom teacher. The students hammered out two ways to get something even as they felt they were losing something, in terms of expression. One compromise allowed them to register doubt or distrust about the law; this was the decision to depict the masked police officer with a snake coming out of his mouth to indicate double-talk/dishonesty (see detail in Figure 1). Another key addition was suggested by the student who had opted out of the project in protest. Behind the Trayvon figure, they would paint protestors' arms raised in resistance, holding megaphones. These arms appeared in the shape of wings behind his shoulders (Figure 2). This adjustment to the mural's design offered a revision of Trayvon's story, or an extension of it, showing how he continues to matter and "live" (as an angel) through the amplified voices of those who protest the injustice of his death.

Because this was a project involving diverse perspectives, participants had to make bids for their individual and collective versions of history, and visions of futurity. They had a sense that they were creating a piece of art about themselves and their world that would offer meaning long after they were gone, to a "public" who would come through the doors for years to come. The students, teacher and administration were forced to reckon with the weight of permanence that was not the norm for a school project. That was the crux of the mural debate, according to the teacher:

What will the artwork mean for little 9th graders entering the building two years, five years, ten years later? To what extent was this going to be an opening for more thought and conversation, or a fuck you left on the wall for future generations?

Figure 2.

Mural detail showing winged "Trayvon" figure

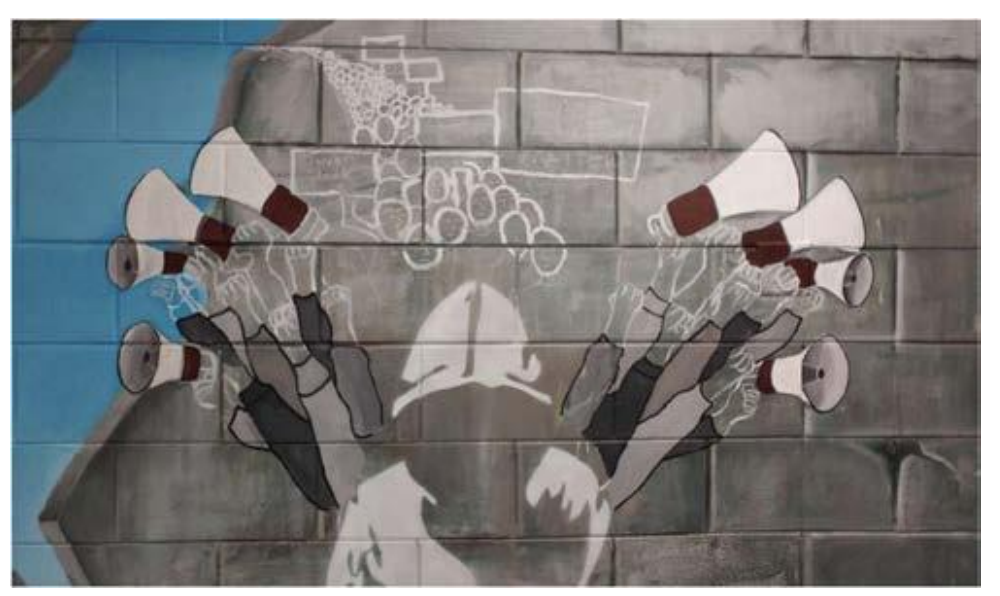


Their version/vision ultimately resulted in a text that was an imperfect compromise; it was an effort to be provocative while somehow making representations of historic and current injustice palatable. This display of art - a mural in a busy school hallway - would remain entangled with the human activities being carried out all around it. The mural pointedly referenced both oppression and resistance, on view in close proximity to the lived social life of the school where these very same systems of oppression played out, from cops in School Resource Officers (SROs) to disproportionate representation of students of color in special education, to unequal disciplinary actions depending on racial identities, to censorship and silencing of voices and stories too painful to see and hear.

The desire to make something less controversial on the part of the administration resulted in renaming and revising the students' interpretation of history as too ugly or inconsiderate for display. In rejecting the visual mingling of police and the KKK, the school maintained its authority over a message, but it fell to the teacher to walk a narrow path between social justice and inclusion for all students in the class, not necessarily the same thing. She was the one who needed to repair damaged relationships, as she had encouraged her students' passionate involvement in calling out inequity, and simultaneously upheld the silencing of their words. She said the controversy made her lose sleep, that she felt like she was ruining the project by not letting student voices, all of them, be aired:

I disagree strongly with probably 60, 70, 80 per cent of what we have to do in public school. But I have two choices, I can participate and push it forward, or I can say forget it and not participate at all. I can push the boundaries as far as I can, or I can walk away.

The struggle to be in ethical relation clashed with a struggle for agency, resulting in partial erasure and revision of the original design of the text's argument. Here the idea of agency as a "force emerging between people and materials" is useful, in that it did not reside in any one individual (Kuby and Crawford, 2018, p. 23).

The TA used this decentered force to set the dialogic problem in motion, and then, he stepped to the side to allow it to move. As a catalyst, he was aided in creating vitality by the time constraint of a 3-week project, which helped the class to maintain their focus on the process of creating public art as political expression. They could not leave an unfinished text on the wall and they needed his help to complete the project. The mural process invited students to take a stand, feel all kinds of ways about it, fight for it, reject it, revise it and figure out how to like some but not all of the argument, and, in fact, to see that an argument is never just words but resonates differently across time and people. In short, the mural was an experience of being affected by and affecting other bodies (Zembylas, 2017, p. 396), and the TA's facilitation was both delicate and a bit wild, as though he taught 30 students to spin plates and then moved in and out of the action, sometimes helping them start spinning, sometimes watching them wobble, sometimes putting them back on track and sometimes watching them collide and break.

\section{Discussion}

TAs in these studies played compelling roles as provocateurs from outside the school. While their participation was brief, and some of the outcomes unexpected, their presence was highly significant. The artists functioned as catalysts that affected and were affected by the becoming happening in the classroom. Their presence set off experiences of embodied literacy and meaning-making that were emergent, resonant, dialogic, cosmopolitan and politically emotionally charged (to name a few!).

TAs were transitory bodies in the room, but they engaged in artistic production that had lasting and resonating effects. The short stay is an outcome of the contingency of this job, an 
economic reality that is not lost on us or other researchers (Pindyck, 2016; Rabkin, 2013). Even when supported at the state level, as with recent national programs in Ireland, South Korea, Brazil and Norway, artist-school partnerships seem to remain perpetually precarious, despite being highly valued for opening possibilities for innovative thinking (Kenny and Morrisey, 2020; Paek, 2018). While artists certainly do work as full-time teachers with the security that comes with that position, we were interested in what happened in part because of the compressed time of the TA visits in these studies. The brevity of their visits allowed for surprising changes, including the ways that it nudged us to see the setting and participants in a different light. The TAs' stranger-status momentarily made strangers of everyone; the newcomer created a generalized awareness of the setting, sometimes dislodging the interaction norms of the class. The newcomer also leaped across the strangeness, working quickly in several days (photographer) or several weeks (muralist). The timing necessitated fast action. Once the artists "landed" in the space, they had to establish an intention, connection, conversation or project. They did not anticipate building long-term relationships with students, and only fleeting ones with the teacher (or cyclical if they come every year), but they needed to make something happen in a compressed period.

The time constraint made it quite reasonable for these TAs to take pedagogical risks. If something did not work out, the problem would not dog the TA for the rest of the year, but only through this visit or set of visits. This often produced an enlivening dynamic. There is a quality of unplanned, open-ended or "unguessed" (Agamben, by way of Pindyck, 2016) to the TA's curriculum that stands in contrast to even the most engaging days of "predetermined (or "guessed") curriculum (Pindyck, 2016, p. 88). Related to the idea of risk, the TAs, unlike teachers, were expected to have a point of view and share it. Artists are not expected to be neutral, because they do not have to evaluate their students. While we believe that there is no such thing as a neutral teacher or neutral anything, there is a performance of political neutrality that teachers enact; they are expected to be fair and see all sides, whereas artists are not. We do not suggest that TAs shoulder the burden of difficult conversations in ways that full-time teachers shirk, but rather, we offer an uncomfortable observation that the outsider status of these two TAs, both of whom were immigrants to the USA and migratory in their employment, brought into this classroom unguessed experiences of emergence and resonance in any given moment.

One such emergence included new forms of participation, as long-term histories for students and even the teacher shifted with the addition of the TAs. In both studies, students who had been quiet throughout the year began to participate with the invitation from the artist's body (perhaps because they arrived with new ears, a different way of listening). Other students spoke up less than they were accustomed to doing, taking a back seat as a response, possibly, to the new dynamic with the audience (the TA). With the addition of TAs, new resonances were born, becoming especially evident in the responses to controversial ideas and signs as they bounced and buzzed across students. The imagined story of the Korean girl in the photograph, and the contested version of American history in the mural reverberated with students; ideas about racial identities circulated when they came into contact with other texts and people, forming and reforming and changing and enlarging through interrogating what is real or true.

Truth was not the goal for the TAs, of course, but both engaged out loud in a quest to know different truths. While the teacher sought opportunities for dialogic interactions and intra-actions with the artwork, the TAs were immigrants to the USA whose bodies conveyed a lived cosmopolitan ethos. They brought their multiple and intersectional identities to this classroom space, just as the students did, and, in asking questions about identities as multiple and shifting, they appeared to value the students as cosmopolitan/ 
translocal intellectuals. Theirs was a dialogic cosmopolitanism. The photographer's focus on the complexity of race and racial identity became a complex source of heteroglossic dialogue for the class. The muralist set in motion a cacophonic collaboration that had no comfortable resolution, although there was a kind of artistic peace with their end product. Both studies were notable for border-crossing dialogues that included efforts to breach the proper distance between photograph and viewer, and offer a proper distance for current and future viewers of the created mural (Chouliaraki, 2011; Silverstone, 2003) in an entanglement of image, the wall on school property that it occupied and the desires of the different participants: artist, students, school administrators and teachers.

We were taken with moments of disruption in both studies that occurred with the presence of the TA. We were especially aware that in working with the artistic projects, raced experiences of students came into contact with other raced experiences when presented visually, both as already-made artwork by the artist (the photograph) and productions made by students (the mural). The embodied presence of TAs made unnatural the equilibrium in the already-dialogic, already-critical classroom; they were legible as highly visible, differently powerful, outsiders. In this way, they offered not only a demonstration and an invitation to create, but they became a new audience of strangers whose very bodies drew out "new potentialities for being, doing and thinking" (Anderson and Harrison, 2010, p. 19) across the social differences in the room.

\section{References}

Ahmed, S. (2004), “Affective economies”, Social Text, Vol. 22 No. 2, pp. 117-139.

Anderson, B. and Harrison, P. (Eds) (2010), "The promise of non-representational theories", Taking Place: Non-Representational Theories and Geography, Ashgate, pp. 1-34.

Anderson, M., Risner, D. and Butterworth, M. (2013), "The praxis of teaching artists in theatre and dance: international perspectives on preparation, practice and professional identity", International Journal of Education and the Arts, Vol. 14 No. 5.

Bakhtin, M.M. (1986), "The problem of speech genres", in Emerson, C. and Holquist, M. (Eds), Speech Genres and Other Late Essays, University of TX Press.

Bloome, D. and Egan-Robertson, A. (1993), "The social construction of intertextuality in classroom reading and writing lessons", Reading Research Quarterly, Vol. 28, pp. 305-333.

Brickell, K. and Datta, A. (Eds) (2011), "Introduction: translocal geographies", Translocal Geographies: Spaces, Places, Connections, Ashgate, pp. 3-20.

Chouliaraki, L. (2011), "Improper distance': towards a critical account of solidarity as irony", International Journal of Cultural Studies, Vol. 14 No. 4, pp. 363-381.

Crampton, A. (2019), "A literacy of armed love: confrontation and desire in aesthetic and critical projects", Studies in Social Justice, Vol. 13 No. 1, pp. 94-117.

Crampton, A., Lewis, C. and Tierney, J.D. (2017), "Proper distance and the hope of cosmopolitanism in a classroom discussion about race", in Zaidi, R. and Rowsell, J. (Eds), Literacy Lives in Transcultural Times, Routledge.

Kahne, J., Middaugh, E. and Allen, D. (2014), "Youth, new media, and the rise of participatory politics", Youth and Participatory Politics Research Network, No. 1, pp. 1-25.

Kenny, A. and Morrisey, D. (2020), "Negotiating teacher-artist identities: 'disturbance' through partnership”, Arts Education Policy Review, doi: 10.1080/10632913.2020.1744052.

Kuby, C.R. and Crawford, S. (2018), "Intra-activity of humans and nonhumans in writers' studio: (re) imagining and (re)defining 'social', Literacy, Vol. 52 No. 1, pp. 20-30. 
Lewis, C. (2020), "Emotion, critical response, and the transformation of signs: the fundamentals of language arts", Language Arts, Vol. 97 No. 4, p. 274.

Lewis, C. and Tierney, J.D. (2013), "Mobilizing emotion in an urban classroom: producing identities and transforming signs in a race-related discussion", Linguistics and Education, Vol. 24 No. 3, pp. 289-304.

Mardirosian, G. and Lewis, Y. (2016), "Introduction", Arts Integration in Education: Teachers and Teaching Artists as Agents of Change: Theory, Impact, Practice, Intellect.

Ngo, B., Lewis, C. and Maloney Leaf, B. (2017), "Fostering sociopolitical consciousness with minoritized youth: insights from community-based arts programs", Review of Research in Education, Vol. 41 No. 1, pp. 358-380.

Paek, K.M. (2018), "Social expectations and workplace challenges: teaching artists in Korean schools", International Journal of Art and Design Education, Vol. 37 No. 3, pp. 507-518.

Pindyck, M. (2016), "Unguessed gestures in effective institutions: poetry's threats to urban schooling", Journal of Curriculum Theorizing, Vol. 31 No. 1, pp. 87-99.

Rabkin, N. (2013), "Teaching artists: a century of tradition and a commitment to change", Work and Occupations, Vol. 40 No. 4, pp. 506-513.

Rasmussen, M. (2009), "The politics of interventionist art: the situationist international, artist placement group, and art workers' coalition", Rethinking Marxism, Vol. 21 No. 1.

Silverstone, R. (2003), "Proper distance: towards an ethics for cyberspace", in Liestol, G., Morrison, A. and Rasmussen, T. (Eds), Digital Media Revisited: Theoretical and Conceptual Innovations in Digital Domains, MIT Press, pp. 469-491.

Soep, E. (2014), Participatory Politics: Next-Generation Tactics to Remake the Public Sphere, MIT Press.

Stornaiuolo, A., Smith, A. and Phillips, N.C. (2017), "Developing a transliteracies framework for a connected world", Journal of Literacy Research, Vol. 49 No. 1, pp. 68-91.

Volosinov, V.N. (1987), Freudianism: A Critical Sketch, in Titunik, I.R. (Ed.), IN University Press. (Original work published 1927).

Vossoughi, S., Hooper, P.A.K. and Escudé, M. (2016), "Making through the lens of culture: visions for educational equity", Harvard Educational Review, Vol. 86 No. 2, pp. 206-232.

Zembylas, M. (2017), "The contribution of non-representational theories in education: some affective, ethical and political implications", Studies in Philosophy and Education, Vol. 36 No. 4, pp. 393-407.

\section{Further readings}

Enriquez, E.J., Kontovourki, S. and Mallozzi, C. (2016), Introduction: Literacies, Learning and the Body: Putting Theory and Research into Pedagogical Practice, Routledge, pp. 3-19.

Kontovourki, S., Johnson, E. and Enriquez, G. (2019), "Call for proposals. Embodiment and literacies: teaching, learning and becoming in a post- world", English Teaching: Practice and Critique. 